\title{
PALEOCLIMATE
}

\section{Recreating an atmosphere}

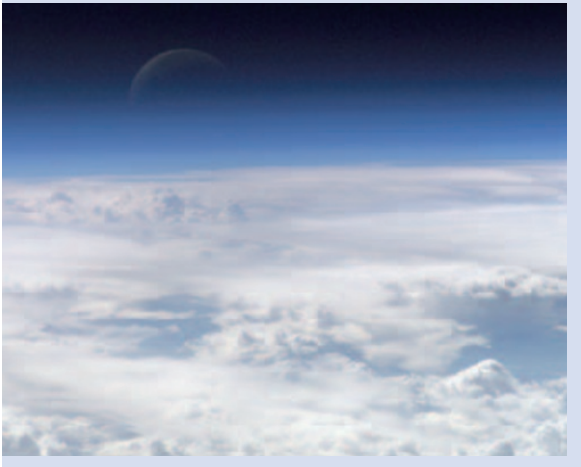

Science doi:10.1126/science.1157638 (2008) Recreating past atmospheres is notoriously difficult, as few clues are left behind in the geological record. For the first time, scientists have reconstructed atmospheric circulation in the Mediterranean during the coldest part of the last glaciation, when ice sheets were at their peak.

Joachim Kuhlemann of the University of Tübingen, Germany, and colleagues used new and previously published glacial data on the height of the Alpine snowline, together with estimates of sea-surface temperature from foraminiferal records, to simulate changes in the three-dimensional structure of the atmosphere between the Last Glacial Maximum, from 23,000 to 19,000 years ago, and the present day. The Mediterranean-wide circulation maps they generate reveal frequent flows of cold polar air from the north, which seem to have been channelled through the frozen mountains of the Alps and the Pyrenees. Together with other atmospheric circulation patterns, the cold air flows appear to mirror and amplify those seen in the Little Ice Age, 500 to 100 years ago, suggesting that characteristic patterns are recurrent.

This reconstruction of the ancient Mediterranean atmosphere provides climate scientists with a wider context for understanding current climatic conditions, and may help in predicting future change.

\section{Anna Armstrong}

to reduce visibility to less than 2 kilometres. During passage of the smoke plume, scattering and absorption of the sun's rays was many times higher than is typical in summer, suggesting that wildfires could cool the Arctic for weeks to months at a time. Modelling showed that such an effect would ultimately depend on factors such as the concentration of the smoke particles, the position of the Sun and the brightness of the land and ocean surface.

Scenarios of future global warming suggest that North American wildfires are likely to become more frequent, and could thus have an increasing role in the Arctic climate.

\section{Olive Heffernan}

\section{ANTHROPOGENIC CHANGE}

\section{Irrigation's influence}

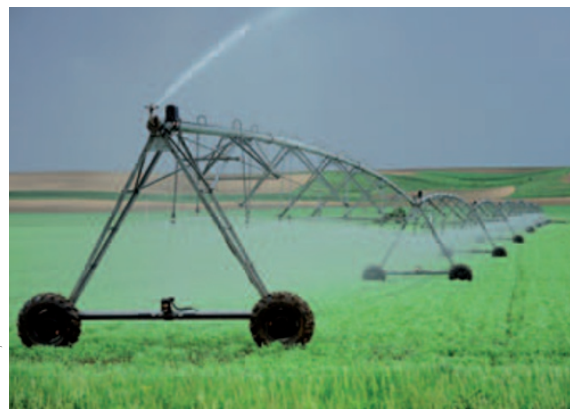

Clim. Dynam.

doi:10.1007/s00382-008-0445-z (2008)

Irrigating crops can influence regional climate considerably, though global temperatures are barely affected, shows a new scientific study. Used to produce over 40 per cent of the world's food, the water from irrigation is equivalent to about two per cent of annual precipitation over land.

William Sacks at the University of Wisconsin-Madison and colleagues estimated how this redistribution of water affects global climate using a coupled model of the land and atmosphere. They found that irrigation cooled the climate by an average of $0.5^{\circ} \mathrm{C}$ over the year in some northern mid-latitude regions, such as the central and southern United States, China, and portions of southern and southeast Asia. In contrast, it warmed much of northern Canada by about $1{ }^{\circ} \mathrm{C}$.

The scientists attribute the drop in temperature in northern mid-latitudes mostly to an evaporation-spurred increase in low-altitude clouds, which block incoming radiation and cause regional cooling. But in high latitudes, changes in atmospheric dynamics favour the development of warming high-altitude clouds. The study suggests that although irrigation has a surprisingly strong effect on regional climate, it has little impact on global mean temperatures.

\section{Alicia Newton}

\section{EXTREME EVENTS}

\section{Models rained out}

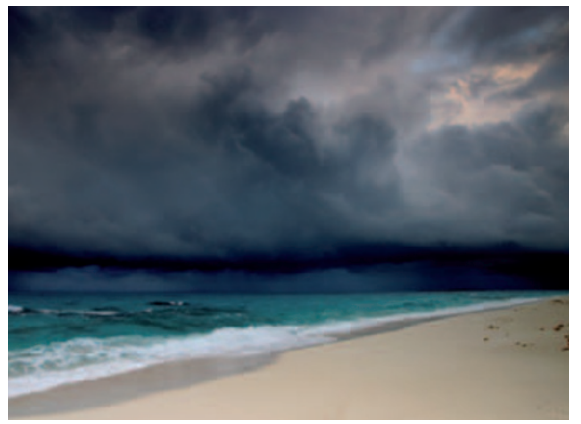

Science doi:10.1126/science.1160787 (2008)

Rising temperatures could make wet regions even wetter than currently predicted by climate models, finds a new study. For the first time, scientists have found direct observational evidence that the most intense of tropical downpours are more frequent during warm periods.

Richard Allan at the University of Reading and Brian Soden at the University of Miami used satellite observations and climate models to 
analyse the response of tropical rainfall to naturally driven El Niño events, which tend to raise temperatures, over the past 20 years. Heavy precipitation pelted tropical oceans more often when El Niño warmed the seas, a trend that was reproduced well by the models. But models were less adept at simulating the frequency of the heaviest rainfall events, which in warm years increased twice as much as predicted.

Among the most dangerous threats from global warming are flooding of rain- swollen rivers and lakes in the tropics. As the latest climate models fall short of reproducing observed precipitation patterns, say the authors, they may also underestimate the extent of future rainfall in these regions.

\section{Anna Barnett}

\section{REGIONAL CLIMATE}

\section{Extreme outlook}

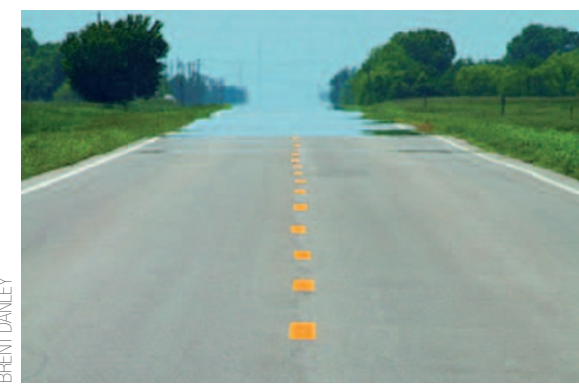

Geophys. Res. Lett. 35, L14703 (2008)

Blistering heat waves will become increasingly common sooner than feared, suggests new research. Some of the most serious consequences of climate change, including fatalities, result from extreme events, yet they have received relatively little attention.

A team led by Andreas Sterl of the Royal Netherlands Meteorological Institute used a large ensemble of climate simulations to investigate how extreme values of climate variables are likely to change in a world with rapid economic growth that balances the use of fossil fuels against alternative energy sources. The researchers predict that extremely high temperatures will not only be more severe and more frequent as the planet warms, they will outpace increases in average temperatures. After correcting for a bias in the model that produces overestimates of extreme temperatures, the researchers still found that by the end of the century, the highest temperatures will far exceed $40{ }^{\circ} \mathrm{C}$ in southern Europe and the midwestern United States, and will reach beyond $50{ }^{\circ} \mathrm{C}$ in Australia,
India, the Middle East and parts of Africa and South America.

The scientists, whose research was motivated partly by the deadly heat wave that struck Europe in 2003, warn that such dangerously high temperatures in densely populated areas should be taken very seriously.

\section{Olive Heffernan}

\section{OCEAN SCIENCE}

\section{Sealing the gap}

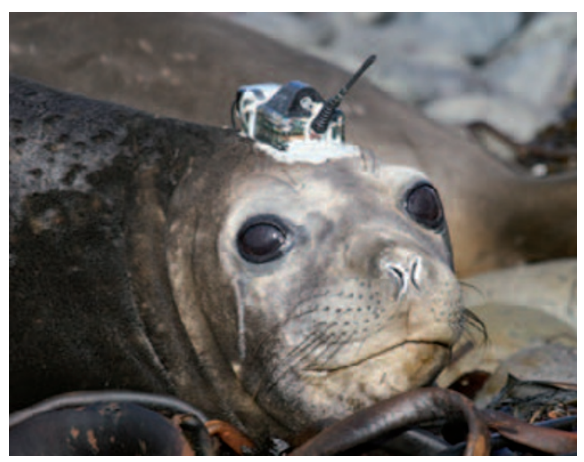

Proc. NatlAcad. Sci. USA

105, 11634-11639 (2008)

For the first time, Antarctic researchers have collaborated with elephant seals to record rates of sea-ice formation in the Southern Ocean. The Antarctic ocean, with its vast tracts of ice and climatically crucial ocean circulation patterns, is particularly vulnerable to warming. But lack of access to the ocean beneath the ice has hampered knowledge of the region.

Jean-Benoit Charrassin of the Natural History Museum, Paris, and colleagues attached temperature and salinity sensors to 58 southern elephant seals, which spend their winters feeding in the Antarctic sea-ice pack and surrounding waters. In total, the seals collected 16,500 depth profiles of the icy ocean during their daily dives in 2004-2005, a 30-fold improvement on other attempts to monitor sea ice. Using the salinity data, the researchers inferred seasonal changes in rates of sea-ice formation, which peaked in early winter. Combining seal data with satellite and buoy observations, they created a uniquely detailed map of ocean fronts - where different water masses meet - in seas south of $60^{\circ}$ latitude.

Data collected by these and other seals will help fill a blind spot in scientists' understanding of the polar oceans - a prerequisite for gauging the region's response to, and role in, climate change.

Anna Armstrong

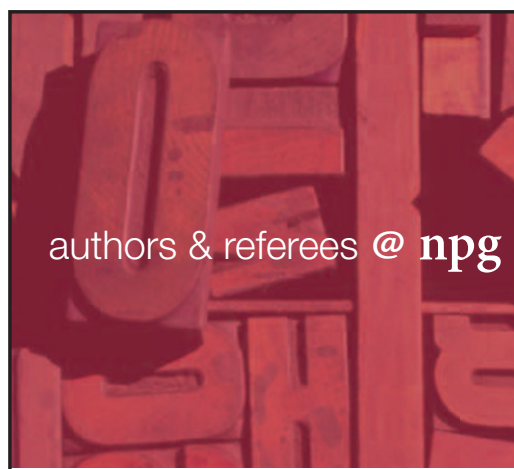

All the information you need for publishing your research with Nature Publishing Group

www.nature.com/authors

- Editorial policies - publication policies for authors and peerreviewers, to help you find an appropriate journal for publication of your work

- Author services - including author and peer-reviewer guidelines and submission pages for our journals

- Peer reviewers - peer review policies, advice for peer-reviewers

- Author benefits - the many benefits of publishing in an NPG journal

Join the discussion:

Join the Nautilus blog for present and future NPG authors

Join the Peer-to-Peer blog discussing the peer review system

www.nature.com/authors 